\title{
The effect of anionic surfactants on aeroponic cultivation of lettuce in space applications
}

\author{
Kamil Janiak ${ }^{1, *}$, Anna Jurga ${ }^{1}$, Joanna Kuźma², and Włodzimierz Breś ${ }^{3}$ \\ ${ }^{1}$ Wroclaw University of Science and Technology, Faculty of Environmental Engineering, \\ Wyb. Wyspianskiego 27, 50-370, Wroclaw, Poland \\ ${ }^{2}$ Wroclaw University of Science and Technology, Faculty of Mechanical and Power Engineering, \\ Wyb. Wyspianskiego 27, 50-370, Wroclaw, Poland \\ ${ }^{3}$ Poznan University of Life Sciences, Department of Plant Nutrition, ul. Zgorzelecka 4, \\ 60-198 Poznan
}

\begin{abstract}
Design of efficient and robust life support systems will require huge effort. In closed systems such as future extra-terrestrial colonies or spaceships, all produced wastes will have to be perfectly purified and all resources will have to be recovered. This isn't possible now even in life support systems built on Earth. Future extra-terrestrial closed life support system will have to be robust and simple as possible to decrease risk of failure and transport costs. One of the attempts to simplify the treatment of wastes is to use greywater as water source in soil-less cultivation without pretreatment. In this paper results of two lab-scale aeroponic experiments are shown. These experiments were aimed at determining possibility of using grey water directly as water source for aeroponic cultivation of lettuce. Two surfactants (SBDS,SMCT) with concentrations varying from 0.08 to $1.5 \mathrm{~g} / \mathrm{L}$ and model grey water (containing SLES surfactant) were tested. Experiments shown that high concentrations of SBDS and SMCT are detrimental for lettuce growth while similar concentration of SLES inhibit but do not stop lettuce growth. With lower concentrations of surfactants growth of lettuce is possible. Moreover results shows decrease in surfactants mass in model grey water used as nutrient solution which may indicate development of bacteria in root zone that are able to use surfactants as substrates.
\end{abstract}

\section{Introduction}

Study presented in this paper focused on checking whether grey water (water from shower, laundry etc.) can be directly used as a water source for lettuce cultivation in aeroponic system. In terms of volume, grey water will be the greatest generated wastewater stream in extraterrestrial colony, as water consumption for laundry and personal hygiene will be much higher that consumption for other needs. Recovery of water from grey water stream is therefore crucial for system to be closed. It might be possible to recover water from grey water stream directly by using it as a water source for crop production. If that is possible then system would be simplified as no grey water treatment unit would be necessary.

* Corresponding author: kamil.janiak@ pwr.edu.pl 
Simplification would lead to lower mass and increased robustness of system - two key factors of extraterrestrial life support system. In this project, idea was tested on lettuce aeroponic cultivation because of its fast growth. Project was divided into two tests: 1. Aeroponic lettuce cultivation supplied with clean water contaminated with anionic surfactants. Concentrations of surfactants were based on data on water consumption and surfactants use in space conditions. That led to very high surfactant concentration. 2. Aeroponic lettuce cultivation supplied with model grey water prepared on basis of typical commercial cleaning products. Concentrations of surfactants were lowered by nearly ten-fold due to death of nearly all plants during first test.

\section{Material and methods}

\subsection{Experiment overview}

Lab-scale facility is made of five, individual modules for aeroponic lettuce cultivation, working in closed loop system. The whole set-up was placed at the Wroclaw University of Science and Technology. The overall look on system is shown in the Figure 1. The scheme of one module is shown in the Figure 2.

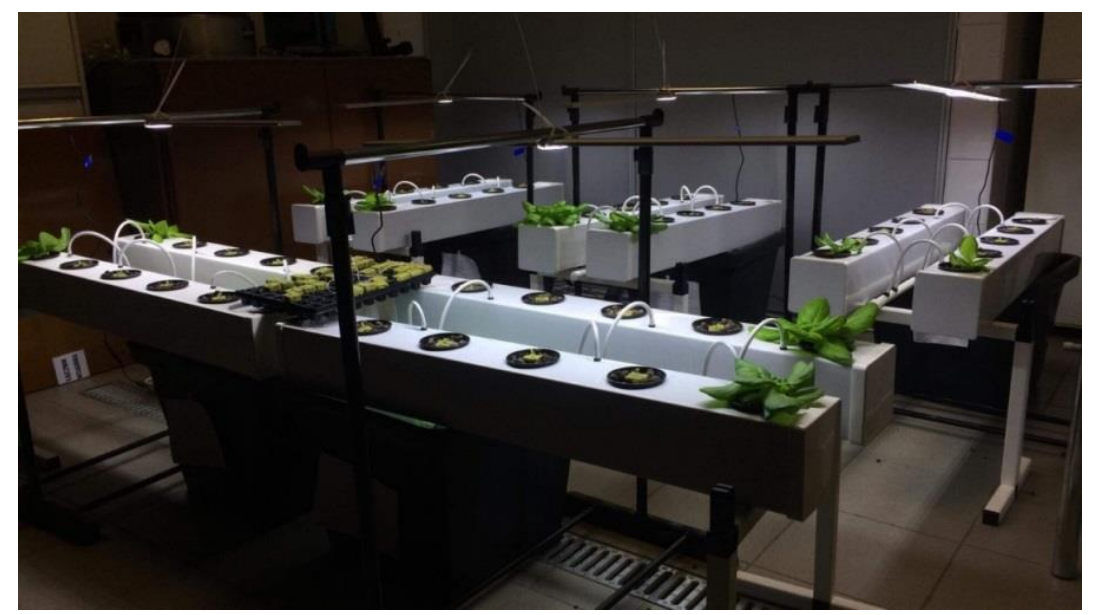

Fig. 1. Overall look on aeroponic system used in project [own source].

Main components of each module are: pump, tank with nutrient solution, piping with nozzles, basket filled with mineral wool and gravelite, drain pipe and LED lamp. In each module up to 10 lettuces are cultivated. Seeds are placed in mineral wool bracket, and after one week are placed in basket filled with gravelite. Recirculation on unused nutrient solution in the module is provided by gravitational flow and drainpipe. However, it should be noted that system should be supplemented with blowers to facilitate movement of solution in case of the microgravity condition. Each tank includes scale intended for water level measurements. Each module is equipped with LED lamps, to ensure plants will conduct photosynthesis [1]. Plants are illuminated for 16 hours by LED lamps, characterized by high efficiency (40\% at maximum light) [2]. Remaining 8 hours plants are set in the "night mode", to facilitate proper growth cycle. Each LED lamp is characterized by luminous flux: $9700 \mathrm{~lm}$. Three recipes for a nutrient solution was taken into consideration [3-5]. After analysis nutrient solution based on Resh [3] recipe was chosen. The nutrient solution composition is presented in the Table 1 . 
Table 1. Nutrient solution composition.

\begin{tabular}{|c|c|c|c|c|c|c|c|c|c|c|c|c|}
\hline $\mathbf{N}^{-N O} \mathbf{3}_{3}$ & $\mathbf{N}-\mathbf{N H}_{4}$ & $\mathbf{P}$ & $\mathbf{K}$ & $\mathbf{M g}$ & $\mathbf{C a}$ & $\mathbf{S}$ & $\mathbf{F e}$ & $\mathbf{Z n}$ & $\mathbf{B}$ & $\mathbf{M n}$ & $\mathbf{C u}$ & $\mathbf{M o}$ \\
\hline 105 & 15 & 50 & 210 & 45 & 190 & 65 & 4 & 0.1 & 0.5 & 0.5 & 0.1 & 0.05 \\
\hline
\end{tabular}

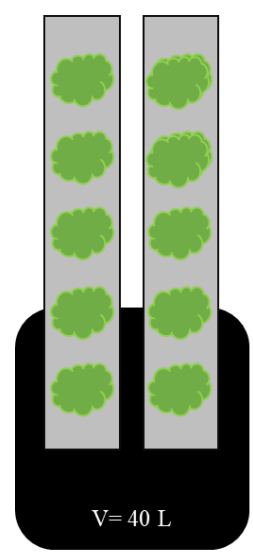

TOP VIEW

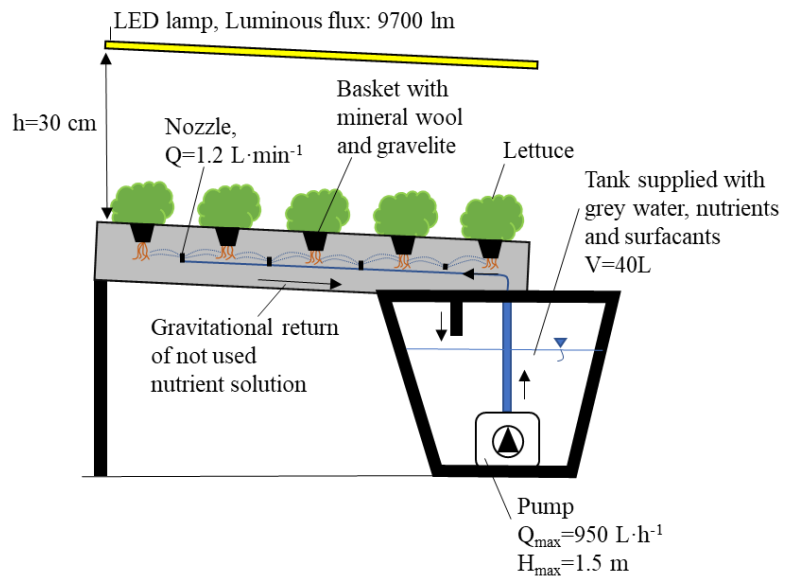

PROFILE VIEW

Fig. 2. Aeroponic module scheme [own source].

\subsection{Research schedule}

The surfactants that are chosen in experiment are predicted to dominate in shower and laundry/dish water in extraterrestrial colony. They are anionic surfactants (Igepon TC-42: sodium N-coconut acid-N-methyl taurate; Sodium methyl cocoyl taurate (SMCT); Sodium dodecylbenzenesulfonate (SDBS); Sodium laureth sulfate (SLES) [3, 6]. Concentration delivered by literature are in the range $0.056-1.5 \mathrm{~g} \cdot \mathrm{L}^{-1}[3,4]$. The most-frequently occurring surfactants in space missions are SMCT and SDBS. Thus these surfactants are chosen for both research phases. In the first phase extreme high concentrations of both surfactants were chosen: $0.5 \mathrm{~g} \cdot \mathrm{L}^{-1}$ and $1.5 \mathrm{~g} \cdot \mathrm{L}^{-1}$ according to data on extraterrestrial grey water composition presented by Wydeven and Golub [6] and Anderson et al. [3]. Water with surfactants and nutrients was supplied to four modules. Fifth module was a reference supplied with clean water enriched with nutrients. The overall scheme of first phase design is shown in the Figure 3. Second phase of research was based on model grey water with known composition, based on worldwide used surfactant: Sodium Laureth Sulfate (SLES) [7]. First module was supplied with model grey water with very high surfactant concentration (such like in extraterrestrial colony), second with much lower surfactant concentration (such like in terrestrial conditions where model grey water stream is much larger and diluted in comparison to grey water created in space mission). Third and fourth module were supplied with surfactant typical for space missions (SBDS and SMCT) but with lowered concentrations in comparison to first phase. Fifth module was a reference supplied with clean water enriched with nutrients. The overall scheme of second phase design is shown in the Figure 4. 

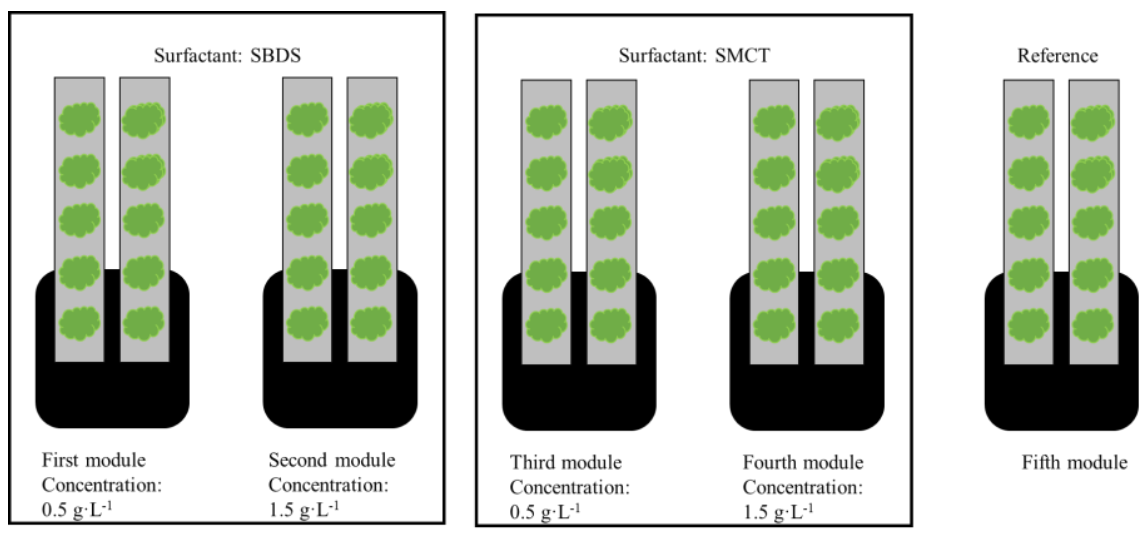

Fig. 3. First phase of experiment overview [own source].
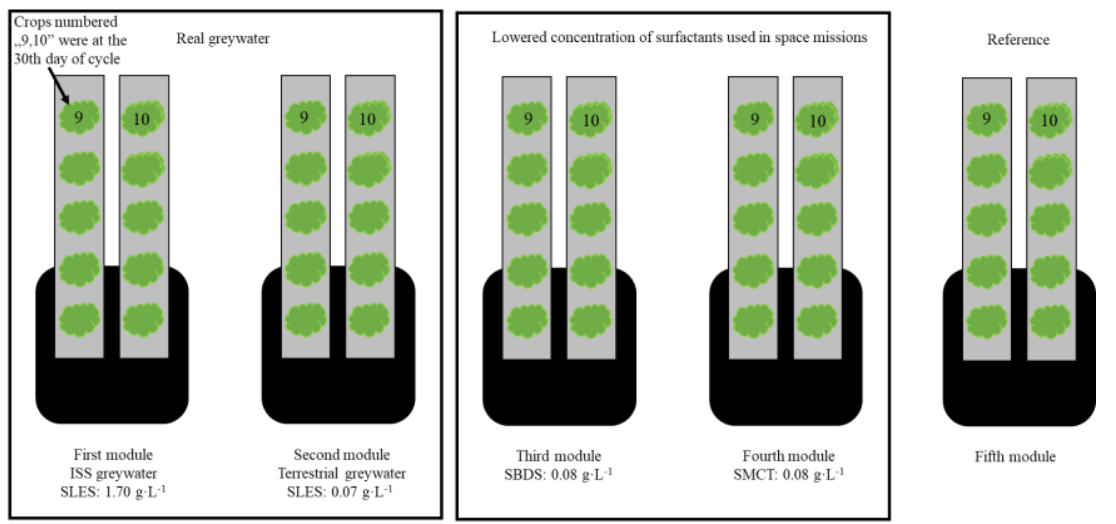

Fig. 4. Second phase of experiment overview [own source].

This phase was essential, since it simulates behavior of plants cultivated on model grey water, with composition designed for the space missions. In this phase influence of stage of development of lettuce on resistance on surfactants was checked, since first phase shown that young seeds could not survive high surfactant concertation. Thus, two lettuces per module were seeded and cultivated on clean water for 14 days and then reseeded and exposed to surfactants (Figure 4: $9^{\text {th }}$ and $10^{\text {th }}$ lettuce in each module). In both phases the air parameters inside the room will be checked (air temperature, relative humidity), nutrient solution parameters in each module (temperature, $\mathrm{pH}$, electrical conductivity was measured using HQ40D Hatch's multi meter), water level in the tanks and concentrations of the most important macronutrients $\left(\mathrm{NH}_{4}, \mathrm{NO}_{3}, \mathrm{PO}_{4}, \mathrm{Mg}, \mathrm{Ca}, \mathrm{K}\right)$ and surfactants. Chemical analyses were made using DR3900 Hatch's Spectrophotometer and dedicated tests. The $\mathrm{pH}$ has a significant impact on the availability of nutrients for plants. When the $\mathrm{pH}$ is too low, many elements are inaccessible, and when $\mathrm{pH}$ is too high leads to a rapid depletion of phosphate and manganese stocks. Plants are able to actively influence the $\mathrm{pH}$ of the nutrient solution. At $\mathrm{pH}$ between 5.2 and 6.5, plants have the best access to nutrients. The amount of ions of dissolved salts in the nutrient solution exerts a force called osmotic pressure (OP), which is a colligative property of the nutrient solutions and it is clearly dependent of the amount of dissolved solutes [8]. To estimate the osmotic pressure of the solution the electrical conductivity (EC) is used. The ideal EC is specific for each crop. However, safe EC values for lettuce is lower than $4 \mathrm{mS} \cdot \mathrm{cm}^{-1}$. Exceeding this value causes the lettuce growth to slow 
down. Nitrogen has a strong influence on the growth and development of plants, but its excess reduces the resistance to damage of the plant and delays blooming. Higher levels of magnesium and calcium cause plants to produce thicker shoots that are more resistant to external factors, however, providing too much of these elements can cause stunted growth. Potassium positively affects the growth of plants and their resistance to external factors, but its excess lowers the content of nutritional elements in the yield. Phosphorus is not a toxic component for plants, but its excess may cause reduced uptake of other elements.

\section{Main results}

\subsection{First phase}

First phase lasted 17 days, since all seeds has died (except for the reference module). All modules were kept in the same external environmental conditions (light intensity, air temperature, air humidity). Air temperature varied from $20.4^{\circ} \mathrm{C}$ to $22^{\circ} \mathrm{C}$, with average value $21.8^{\circ} \mathrm{C}$. Air humidity varied from $32 \%$ to $50 \%$, with average value $39.4 \%$. The average nutrient solution temperature was $19.8^{\circ} \mathrm{C}$ for all modules. The $\mathrm{pH}$ in module 5 was rather stable in the average value 7.82. The other modules were more variable. The EC was characterized by an upward trend in each of the modules. In general, the $\mathrm{pH}$ and EC was in the range: $7.19-7.82 \mathrm{mS} \cdot \mathrm{cm}^{-1} ; 1.99-2.25 \mathrm{mS} \cdot \mathrm{cm}^{-1}$ respectively. The reduced growth of seedlings compared to module 5 was noticeable from the beginning of cultivation. After 17 days of cultivation nearly all seedlings has died.

\subsection{Second phase}

Second phase lasted 42 days. Internal parameters in the room was the same for each module. the same external environmental conditions (light intensity, air temperature, air humidity). Air temperature varied from $20^{\circ} \mathrm{C}$ to $23^{\circ} \mathrm{C}$, with average value $21.8^{\circ} \mathrm{C}$. Air humidity varied from $30 \%$ to $56 \%$, with average value $43 \%$. The average nutrient solution temperature was $19.6-19.8^{\circ} \mathrm{C}$ for all modules. Initially, the $\mathrm{pH}$ increased, after that it systematically fell to the optimal value in module $2-5$. In module 1 drop of the $\mathrm{pH}$ was much slower, which may be the result of the less developed aerial part and the root system in the plant due to inhibited growth of plants exposed to high surfactant concentration. In module 1-3 and 5 EC was kept at a safe level. However, in module 4, this level has been exceeded, probably due to the fact that the concentration of positive ions in module 4 was the highest. In the Figure 5 the change in surfactant load in time for each module is presented. It can noticed that at the end of the cycle, the surfactant content has dropped below $2.5 \%$ of the initial value for each of the modules. Probably surfactants in water were decomposed by bacteria thriving on roots. These results are very promising as they may indicate that bacteria growing on roots have ability to decompose surfactants and act as a purification system.
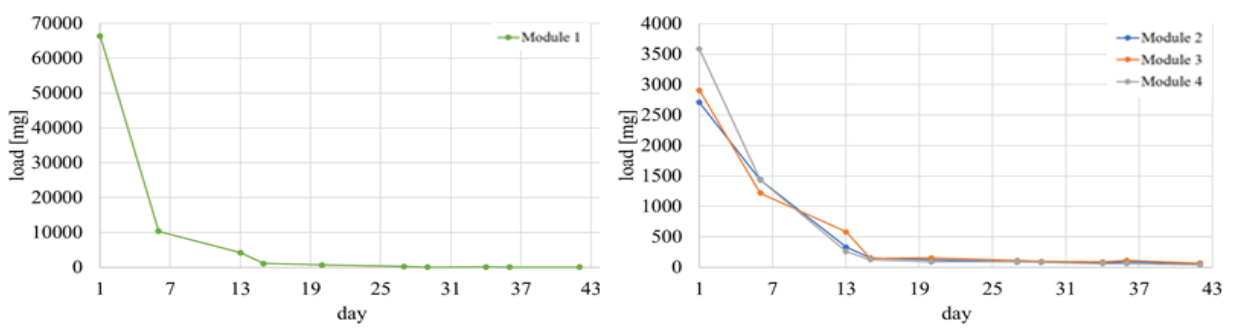

Fig. 5. The content of surfactants in each of the modules in the second phase of the experiment [own source]. 
The harvested crop on the last day of phase two is shown in the Figure 6. Plants in the first module (highest surfactant concentration) were characterized by a significantly smaller size. Their root system was poorly developed and the roots were short. The different colour of the leaves in this module compared to other modules is worth noticing. It was deep green. Plants cultivated from modules $2-5$ had a similar stage of development of the edible part and also were similar visually. However, their root systems differed among themselves. Second module root zone could be characterized comparable to the first module. Probably since the same type of surfactant was used in both modules. Root systems in module 3 and 4 were strongly extended on length. However, there were no side systems on the main roots. In the reference module (module 5) roots were long and got large numbers of side systems on the main roots.

Differences between the modules 1 and 2-5 can also be seen in comparison to total mass (total mass of edible and inedible). Comparison between the modules can be seen in the Figure 7 . The total wet mass obtained in module 1 was lower in relation to the other modules in the range of $67 \%$ to $73 \%$. Despite differences in growth for different modules, the ratio of edible to total weight remained at a similar level, oscillating at the average value. The average ratio of the edible to total weight for lettuces $1-8$ is $91.2 \%$ and for lettuces $9-10$ is $95.3 \%$. The relationship can be noticed that the older the lettuce, the greater the proportion of its total weight. This is noticeable in each of the modules.

It can be also noticed that although the biggest yield of the lettuces " $1-8$ " is observed in module 5, the biggest total mass is observed in module 3 . This might support the hypothesis, that some surfactants at the appropriate concentration may support plant growth. Module 5 is also characterized by the highest production of edible biomass and the smallest percentage of inedible biomass. Comparing the received data to the data from the [2] it can be seen that the percentage of inedible biomass for module 1-4 is similar, and for module 5 is lower. Detailed study on elements content in harvested lettuces (both edible and inedible parts) would give the opportunity to present a balance of mass and loads in system and will show the exact flow of elements in the system. However, this analysis are still ongoing and will be shown in future publication.
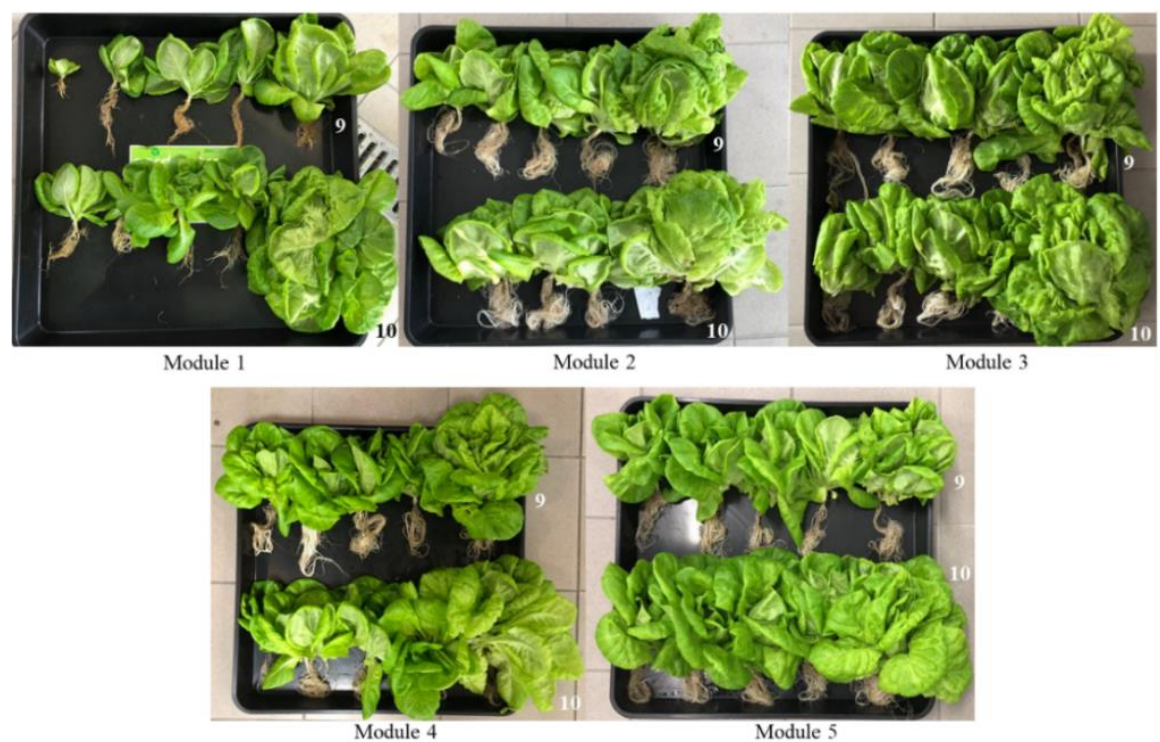

Fig. 6. View on the harvested crop from five modules on the last day of phase two test 27/02/2019 [own source] (Crops numbered " $9-10$ " were older than the others " $1-8$ " by 30 days). 


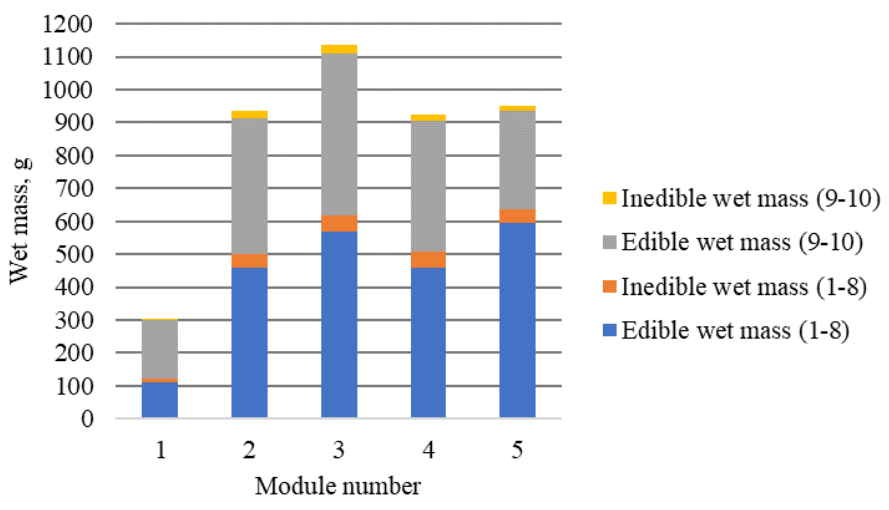

Fig. 7. List of wet masses for each module divided into edible and non-edible parts and distinguishing between lettuces 1-8 and 9-10 [own source] (Crops numbered "9-10" were older than the others "1-8" by 30 days).

\section{Summary}

The results can be summarized:

- $\quad$ nutrient solution contaminated with SDBS or SMCT in concentration of $1.5 \mathrm{~g} \cdot \mathrm{L}^{-1}$ is causing total inhibition of lettuce growth, which leads to cultivation failure on the early stage of cultivation,

- $\quad$ nutrient solution contaminated with model grey water containing SLES surfactant in concentration $c a .1 .5 \mathrm{~g} \cdot \mathrm{L}^{-1}$ would partially inhibit lettuce growth which leads to much lower crops in comparison to cultivation on clean water,

- when SDBS, SMCT or SLES surfactant concentrations are lowered, cultivation is possible and leads to crop yield is comparable to cultivation on clean water,

- when lettuce is cultivated on clean water for first 14 days and exposed to surfactants after that time, it is stronger and is able to resist negative influence of surfactants,

- it seems that bacteria thriving on lettuce roots are able to decompose surfactants contained in grey water,

- the presence of surfactants in the nutrient solution affects mass and morphology of the plant roots

\section{Conclusions}

Reffering to the obtained results it can be concluded that the grey water can be used as a source of water needed to prepare nutrient solution in aeroponic systems, however, the concentration of surfactants cannot exceed a certain level. This level depends on the the stage of plant development and type of the surfactants. However analyzing the obtained results, it can be noticed that surfactants have a negative effect on the growth of edible biomass. For extraterrestrial solutions continuation of research on aeroponics supplied with grey water may lead to gaining knowledge on which crops and which surfactants provide best results. If roots are truly settled with bacteria able to decompose surfactants it may lead to development of aeroponic system that is providing not only food and oxygen but also treatment solution for surfactants. It is also possible that root area can be settled with bacteria able to decompose and treat black water (feces and urine). That would lead to tremendous simplification of waste streams treatment process. Aeroponics is a system that saves energy and water in addition. Due to the optimal supply of oxygen and nutrients it allows to obtain a larger yield in a shorter 
time, therefore advancing knowledge in this topic is beneficial not only in the context of space applications, but also Earths, especially in places where access to water and farmland is limited. Future research should addressed:

1. Checking the nutritional value of plants fed with nutrient solution based on gray water.

2. Repetition of tests on grey water with emphasis on roots bacteria ability to decompose surfactants.

3. Tests on salty water to check whether cultivation on salt water is possible.

4. Optimization of aeroponics parameters for different crops cultivations.

5. Checking the possibilities of growing plants, of which the root is an edible part (such as carrots, celery, beetroot, radish etc.) - evaluation of their taste and aesthetic values.

6. Checking the possibilities of growing grains (for example rice or wheat) with the use of an aeroponic installation.

7. Checking plants supplied by grey water for toxicity and possibility of human consumption.

This project received seed funding from the Dubai Future Foundation through Guaana.com open research platform.

\section{References}

1. G. Boscheri, C. Lobascio, M. M. Lamantea, L. Locantore, V. Guarnieri, D. Schubert, The EDEN ISS Rack-Like Plant Growth Facility (46 ${ }^{\text {th }}$ International Conference on Environmental Systems, 2016)

2. M. S. Anderson, M. K. Ewert, J. F. Keener, Life Support Baseline Values and Assumptions Document (National Aeronautics and Space Administration Washington, D.C. Report No. NASA/TP-2015-218570, 2018)

3. H. M. Resh, Hydroponic food production: a definitive guidebook for the advanced home gardener and the commercial hydroponic grower (CRC Press, 2016)

4. K. Yamazaki, Nutrient solution culture (Pak-kyo Co., Tokyo, Japan, 41, 1982)

5. D. S. Domingues, H. W. Takahashi, C. A. Camara, S. L. Nixdorf, Computers and Electronics in Agriculture 84, 53-61 (2012)

6. T. Wydeven, M. A. Golub, Generation rates and chemical compositions of waste streams in a typical crewed space habitat (National Aeronautics and Space Administration, Ames Research Center; Moffett Field, CA. Report No. NASA-TM102799, 1990)

7. H. W. Stache, Anionic Surfactants: Organic Chemistry (Surfactants Science Series, ISBN 0824793943, New York, U.S.A, 1995)

8. D. Landowne, Cell Physiology (McGraw-Hill Medical Publishing Division, ISBN 0071464743, Miami, FL., U.S.A., 2006) 